\title{
Frailty and cognitive impairment among community-dwelling elderly
}

\author{
Fragilidade e alteração cognitiva em idosos comunitários \\ Mariana Asmar Alencar¹, João Marcos Domingues Dias', Luisa Costa Figueiredo', Rosângela Corrêa Dias
}

\begin{abstract}
The aim was to evaluate associations between frailty status and cognitive decline and the incidence of cognitive impairment over 12-month period. Two hundred seven older adults were assessed. Frailty was defined as having at least three of the following criteria: weight loss, weakness, exhaustion, slowness, and low level of activity. Cognitive decline was assessed using the Mini Mental State Examination (MMSE) and Clinical Dementia Rating Scale (CDR). Relative risk (RR) was calculated with a 95\% confidence interval (Cl). Frailty was associated with subsequent cognitive decline in 12-month when assessed using the MMSE ( $p=0.005 ; \mathrm{RR}=4.6 ; 95 \% \mathrm{Cl} 1.93-11.2)$. No association was found between frailty and cognitive decline measured by the CDR ( $p=0.393 ; R R=2.1 ; 95 \% \mathrm{Cl} 0.68-6.7)$ or between frailty and the incidence of cognitive impairment $(p=0.675 ; R R=1.2 ; 95 \% \mathrm{Cl} 0.18-8.3$ ). These findings reveal an association between frailty and subsequent cognitive decline when measured by the MMSE, even within a short period of time.
\end{abstract}

Key words: aged, frail elderly dementia.

\section{RESUMO}

O objetivo foi avaliar a associação entre fragilidade e o declínio cognitivo e a incidência de alteração cognitiva, em 12 meses. Foram avaliados 207 idosos. Fragilidade foi definida como ter pelo menos três dos critérios: perda de peso, fraqueza, exaustão, lentidão e baixo nível de atividade. $O$ declínio cognitivo foi avaliado pelo Mini Exame do Estado Mental (MEEM) e pela Escala Clínica de Demência (CDR). Foi calculado o risco relativo (RR) com intervalo de confiança (IC) de 95\%. A fragilidade está associada a um declínio subsequente da função cognitiva em 12 meses, quando medida pelo MEEM ( $p=0,005$; RR=4,6; IC95\% 1,93-11,2). Não foi verificada associação entre fragilidade e o declínio da função cognitiva pela CDR ( $p=0,393 ; R R=2,1 ; \operatorname{IC} 95 \%$ 0,68-6,7) e entre a fragilidade e a incidência da alteração cognitiva ( $p=0,675 ; R R=1,2$; IC95\% 0,18-8,3). Este estudo mostrou que, mesmo em um período curto, existe associação entre a fragilidade e um declínio subsequente da função cognitiva, quando medida pelo MEEM.

Palavras-Chave: idoso, idoso fragilizado, demência.

Frailty is an important geriatric syndrome that results from a reduction in the reserves of multiple systems, leading to a state of increased vulnerability to stressors ${ }^{1,2}$. Frailty is generally associated with an increased risk of functional decline, institutionalization, hospitalization, and death ${ }^{1-3}$ and has therefore been described as an important clinical and public health problem that merits further study ${ }^{1}$.

Recent studies have identified an association between frailty and subsequent cognitive decline in 3- and 12-year cohorts $^{4,6-8}$. Moreover, associations have been found between frailty and an increased incidence of mild cognitive impairment $^{7}$ and Alzheimer's diease ${ }^{6}$. In a study involving frail older adults with and without cognitive impairment, Ávila-Funes et al. ${ }^{5}$ report that cognitive impairment increases the predictive validity of frailty for the occurrence of adverse outcomes in a four-year period.

Longitudinal studies report that the progression rate of cognitive impairment among older adults ranges from 1 to $2 \%$ a year ${ }^{9}$. Moreover, older adults with cognitive impairment progress to more severe stages on an annual basis and the conversion rate to dementia can reach 10 to $30 \%$ a year ${ }^{10,11}$. However, there is little knowledge on the factors related to progressive cognitive impairment within a one-year period and whether this progression is associated with frailty. Thus, gaining a better understanding of the association between frailty and cognitive impairment within a short period of time may assist in establishing strategies aimed at prevention and treatment.

Study carried out at Universidade Federal de Minas Gerais (UFMG), Belo Horizonte MG, Brazil.

${ }^{1}$ Department of Physical Therapy, UFMG, Belo Horizonte MG, Brazil.

Correspondence: Mariana Asmar Alencar; Rua Piauí 741 / apto 901,30150-320 Belo Horizonte MG - Brasil; E-mail: masmaralencar@yahoo.com.br Conflict of interest: There is no conflict of interest to declare.

Received 15 October 2012; Received in final form 09 November 2012; Accepted 16 November 2012. 
The aim of the present study was to evaluate associations between frailty status and cognitive decline and the incidence of cognitive impairment over a 12-month period among community-dwelling older adults.

\section{METHODS}

\section{Sample}

The participants of the present investigation made up part of a 12-month cohort study developed at the Jenny de Andrade Faria Institute of Elderly and Women's Healthcare at the University Hospital of the Universidade Federal de Minas Gerais (UFMG) in Belo Horizonte city, Brazil. This institution offers specialized public outpatient care for older adults.

To ensure a representative sample, the sample size was based on the number of older adults enrolled at the institute and previous studies on frailty, considering an $80 \%$ statistical power and $5 \%$ level of significance. Simple randomized probabilistic sampling was used to determine the number of participants.

The sample was made up of 207 community-dwelling individuals aged 65 years or older with and without cognitive impairment. The following were the exclusion criteria: bed-ridden individuals, those restricted to a wheelchair and those in the terminal stage; hearing or vision impairment that would impede the performance of the tests; severe consequences of a stroke; severe stage Parkinson's disease that would impede the performance of the tests; and severe dementia (grade 3), based on the criteria of the Clinical dementia rating $(\mathrm{CDR})^{12,13}$.

This study was received approval from the Human Research Ethics Committee of the UFMG (Brazil) under Process n ETIC 220/09. All participants or guardians signed a statement of informed consent.

\section{Assessment of frailty}

Frailty was assessed using the criteria developed by Fried et al. ${ }^{2}$. The following characteristics were considered: unintentional weight loss $\geq 4.5 \mathrm{~kg}$ or $\geq 5 \%$ of body weight in previous year; weakness, defined by handgrip strength, adjusted for gender and body mass index; exhaustion, indicated by self-reports of fatigue and identified by two questions on the Center for Epidemiologic Studies Depression scale; slowness, assessed by the time (in seconds) needed to walk a distance of 4.6 meters, adjusted for gender and height; and low physical activity level, measured by the amount of weekly energy spent, using the short version of the Minnesota Leisure Time Activity Questionnaire. Participants meeting three or more criteria were classified as frail; those meeting one or two criteria were classified as pre-frail and those meeting none were considered non-frail ${ }^{2}$.

\section{Assessment of cognitive function}

Cognitive function was assessed using a two-stage screening process (sequential testing) to increase the accuracy of the evaluation, thereby enhancing the specificity of the measurement ${ }^{14,15}$. The Mini Mental State Examination (MMSE) was first administered to all participants ${ }^{16,17}$. Those who tested positive for altered cognition then underwent the Brief Cognitive Screening Battery (BCSB) ${ }^{14,15}$. Only those participants who tested positive for altered cognition on both on tests were classified as having cognitive impairment ${ }^{14,15}$. The cutoff scores for MMSE were 17/18 for illiterate participants, 20/21 for those with one to four years of schooling, $23 / 24$ for those with five to eight years and $25 / 26$ for those with nine or more years of schooling ${ }^{14,18}$. On the BCSB, individuals with a score of 7 or less were considered positive for altered cognition ${ }^{18}$.

The CDR was used for the classification of the degree of dementia $^{12,13}$. This assessment tool has six cognitive-behavioral categories: memory, orientation, judgment and problem solving, community affairs, home and hobbies and personal care. Each category is scored as 0 (no alteration), 0.5 (questionable), 1 (mild dementia), 2 (moderate dementia) or 3 (severe dementia), except personal care, which does not include a score of 0.5. The final classification is based on the analysis of these categories using a set of rules established and validated by Morris ${ }^{13}$ and elderly individuals with cognitive impairment are classified with questionable $(\mathrm{CDR}=0.5)$, mild $(\mathrm{CDR}=1)$, moderate $(\mathrm{CRD}=2)$ or severe $(\mathrm{CDR}=3)$ dementia $^{12,13}$. In the present study, the classification of the participants regarding the degree of dementia was established through a consensus between two researchers who had previously undergone training for use of the CDR and obtained certification from the Alzheimer's Disease Research Center, Washington University (St. Louis, MO, USA).

\section{Socio-demographic and clinical characteristics}

The socio-demographic characteristics analyzed were age, gender, schooling and marital status.

Nutritional status was measured and classified based on the body mass index (BMI), using the cutoff points recommended for elderly individuals: $<22 \mathrm{~kg} / \mathrm{m}^{2}$ was considered underweight; $\geq 22 \mathrm{~kg} / \mathrm{m}^{2}$ and $\leq 27 \mathrm{~kg} / \mathrm{m}^{2}$ was considered the ideal range; and $>27 \mathrm{~kg} / \mathrm{m}^{2}$ was considered overweight ${ }^{19}$.

Medical conditions were analyzed based on the previous 12 months, investigating hospitalization, falls and number of medications in regular use. To identify diseases and comorbidities, the participants were asked if they had a physician-determined diagnosis of heart disease, hypertension, stroke, diabetes, cancer, rheumatic disease, lung disease, osteoporosis, neurologic disease, urinary incontinence or fecal incontinence.

The short version of the Geriatric Depression Scale (GDS-15) ${ }^{20,21}$ was used to assess depressive symptoms in 
elderly individuals without cognitive impairment, with a cutoff point of 5/6 (non-case/case) ${ }^{21}$. For individuals with cognitive impairment, depressive symptoms were assessed using the Cornell Depression Scale in Dementia, for which a score of eight or more points was considered positive screening for depressive symptoms ${ }^{22,23}$.

The functional capacity was assessed by determining the capacity to perform basic activities of daily living (BADL), instrumental activities of daily living (IADL), and advanced activities of daily living (AADL). BADL were evaluated using the Katz Scale $^{24}$, which assesses the degree of dependence on six basic activities: feeding, sphincter control, transfers, personal hygiene, dressing and bathing. The subject is classified based on the number of activities on which he/she is dependent on others. The Lawton Scale ${ }^{25}$ was used for the evaluation of IADL; this scale investigates the ability to perform seven activities: using a telephone, using transportation, shopping, making meals, doing household chores, taking medications, and managing money. The score ranges from 7 to 21 points, with lower scores denoting greater dependence. The evaluation of AADL involves 12 activities of greater complexity: paying visits, receiving guests, going to church or temple, participating in community centers, participating in social get-togethers, participating in cultural events, driving a car, taking a day trip out of town, taking a longer trip, doing volunteer work, doing paid work and participating on boards or councils ${ }^{26}$. The total number of the different response options for each activity ("still does", "no longer does" and "never did") was determined.

\section{Procedures}

The participants in the present cohort study were evaluated at baseline and after 12 months. For the evaluation of those with cognitive impairment, the primary caregiver provided information on weight loss, level of physical activity, exhaustion, socio-demographic characteristics, medical conditions and functional aspects ${ }^{27}$. The use of the primary caregiver as the respondent was based on the difficulty elderly individuals with cognitive impairment have remembering facts and properly evaluating their physical and functional capacities, which compromises the reliability and accuracy of the information ${ }^{27}$. Individuals without cognitive impairment (according to the screening process) answered the questions themselves.

In the present study, the incidence of cognitive impairment was considered the number of new cases (participants with negative screening at baseline and positive screening after 12 months). Cognitive decline was determined based on changes in the MMSE score and CDR classification.

\section{Statistical analysis}

The Shapiro-Wilk test was first employed to determine the distribution of the data with regard to normality. For the socio-demographic variables, health conditions and functional capacity, either Pearson's $\chi^{2}$ test or Fisher's exact text was used for the comparison of non-frail, prefrail and frail individuals regarding categorical variables and either the F test (ANOVA) or the Kruskal-Wallis test was used for the continuous variables. The variation in the MMSE exam between baseline and the 12-month follow-up evaluation was used to determine the progression of cognitive impairment. The association between the change in MMSE score and frailty was determined using the $\mathrm{F}$ test. Paired comparisons of the frailty categories were performed using Tukey's post hoc test. Pearson's $\chi^{2}$ test was employed for the evaluation of the progression of cognitive impairment based on the CDR classification. Fisher's exact test was used to determine associations between the incidence of cognitive impairment and the degrees of frailty (non-frail, pre-frail and frail). Relative risk (RR) with a 95\% confidence interval (CI) was calculated for each variable. The statistical analysis was performed using the R program (version 2.7.1 and the Epi-Info program (version 6.04), both of which are in the public domain. The level of significance was set to $5 \%(p<0.05)$.

\section{RESULTS}

Among the 207 older adults evaluated at baseline, 47 $(22.7 \%)$ were classified as non-frail, 112 (54.1\%) were classified as pre-frail and $48(23.2 \%)$ were classified as frail. Tab 1 displays the socio-demographic characteristics and health conditions of the patients at baseline according to the degree of frailty. Individuals classified as frail were older, had a lower educational level, lower BMI and performed fewer IADL and AADL in comparison to pre-frail and non-frail individuals. Frail individuals also had a greater frequency of positive screening for depression and dependence on BADL. Approximately $6.4 \%$ of non-frail individuals, $25 \%$ of pre-frail individuals and $58.3 \%$ of frail individuals had positive screening for cognitive impairment based on the twostage evaluation process.

Throughout the course of the study, $87.9 \%(n=182)$ of the cohort participated in the 12-month evaluation, $5.8 \%(n=12)$ had died and $6.2 \%(n=13)$ were lost to follow-up. Data from the latter two groups $(n=25)$ were not used in the analysis of the cognitive decline and incidence of cognitive impairment. Tab 2 and 3 display the data on the incidence and progression of cognitive impairment in the 12-month period according to the baseline classification of frailty. The proportion of new cases of cases of cognitive impairment was $4.9 \%$ among nonfrail individuals, 8.9\% among pre-frail individuals and $13.3 \%$ among frail individuals. However, no statistically significant differences among groups were found with regard to the incidence of cognitive impairment ( $\mathrm{p}=0.675)$. 
Table 1. Socio-demographic characteristics and health status of participants at baseline according to classification of frailty.

\begin{tabular}{|c|c|c|c|c|}
\hline & $\begin{array}{l}\text { Non-frail } \\
\text { Mean } \pm S D\end{array}$ & $\begin{array}{l}\text { Pre-frail } \\
\text { Mean } \pm S D\end{array}$ & $\begin{array}{c}\text { Frail } \\
\text { Mean } \pm S D\end{array}$ & $p$-value \\
\hline Age (years) & $74.53 \pm 6.4$ & $78.27 \pm 8.02$ & $82.33 \pm 7.13$ & $<0.001$ \\
\hline Schooling (years) & $3.7 \pm 3.6$ & $3.2 \pm 2.8$ & $1.8 \pm 0.5$ & 0.008 \\
\hline Number of comorbidities & $2.77 \pm 1.60$ & $3.16 \pm 1.60$ & $3.31 \pm 1.60$ & 0.216 \\
\hline IADL & $20.28 \pm 1.72$ & $17.88 \pm 3.77$ & $15.04 \pm 4.35$ & $<0.001$ \\
\hline \multirow[t]{2}{*}{$\begin{array}{l}\text { AADL } \\
\text { "still does" } \\
\text { "no longer does" }\end{array}$} & $\begin{array}{l}5.87 \pm 1.72 \\
2.6 \pm 1.47\end{array}$ & $\begin{array}{l}5.24 \pm 1.77 \\
2.71 \pm 1.63\end{array}$ & $\begin{array}{l}3.69 \pm 1.86 \\
3.73 \pm 1.81\end{array}$ & $\begin{array}{l}<0.001 \\
<0.001\end{array}$ \\
\hline & $\mathrm{n}(\%)$ & $n(\%)$ & $\mathrm{n}(\%)$ & $\mathrm{p}$-value \\
\hline Women & $35(74.5)$ & $86(76.8)$ & $38(79.2)$ & 0.863 \\
\hline Marital status - widowed & $18(38.3)$ & $60(53.6)$ & $28(58.3)$ & 0.343 \\
\hline $\begin{array}{l}\text { BMI } \\
\text { Underweight }(<22) \\
\text { Ideal weight }(22-27) \\
\text { Overweight }(>27)\end{array}$ & $\begin{array}{l}5(10.6) \\
27(57.4) \\
15(31.9)\end{array}$ & $\begin{array}{l}28(25.0) \\
50(44.6) \\
34(30.4)\end{array}$ & $\begin{array}{l}18(37.5) \\
14(29.2) \\
16(33.3)\end{array}$ & 0.016 \\
\hline Cognitive impairment & $3(6.4)$ & $28(25)$ & $28(58.3)$ & $<0.001$ \\
\hline MMSE & $23.66 \pm 4.14$ & $21.1 \pm 5.50$ & $17.02 \pm 5.43$ & $<0.001$ \\
\hline Depression - positive screening & $6(12.8)$ & $41(36.6)$ & $25(52.1)$ & $<0.001$ \\
\hline Number of medications & $4.17 \pm 2.21$ & $4.46 \pm 2.23$ & $5.15 \pm 2.02$ & 0.075 \\
\hline $\begin{array}{l}\text { BADL } \\
\text { Independent on all activities }\end{array}$ & $37(78.7)$ & $69(61.6)$ & $23(47.9)$ & 0.033 \\
\hline Total & $n=47(22.7)$ & $n=112(54.1)$ & $\mathrm{n}=48(23.2)$ & \\
\hline
\end{tabular}

SD: standard deviation; BMI: body mass index; MMSE: Mini Mental State Exam; BADL: basic activities of daily living; IADL: instrumental activities of daily living; AADL: advanced activities of daily living.

Table 2. Rate of incidence and progression between degrees of cognitive impairment according to classification of frailty (baseline and 12 -month follow-up)*.

\begin{tabular}{|c|c|c|c|c|c|c|c|}
\hline \multirow{4}{*}{$\begin{array}{l}\text { Classification } \\
\text { at baseline }\end{array}$} & \multicolumn{7}{|c|}{ Progression from baseline to one year } \\
\hline & \multicolumn{7}{|c|}{ Classification after one year } \\
\hline & $\begin{array}{c}\text { No alteration } \\
(C D R=0)\end{array}$ & $\begin{array}{c}\text { Questionable } \\
\text { (CDR=0.5) }\end{array}$ & $\begin{array}{c}\text { Mild } \\
(\mathrm{CDR}=1.0)\end{array}$ & $\begin{array}{l}\text { Moderate } \\
(C D R=2.0)\end{array}$ & $\begin{array}{c}\text { Severe } \\
(\mathrm{CDR}=3.0)\end{array}$ & Death** & Total \\
\hline & $\mathrm{n}(\%)$ & $\mathrm{n}(\%)$ & $\mathrm{n}(\%)$ & $\mathrm{n}(\%)$ & $\mathrm{n}(\%)$ & $\mathrm{n}$ & $\mathrm{n}(\%)$ \\
\hline Non-frail & & & & & & & $(n=43)$ \\
\hline $\begin{array}{l}\text { No alteration } \\
\text { Questionable } \\
\text { Mild } \\
\text { Moderate }\end{array}$ & $\begin{array}{c}39(95.1) \\
0(0) \\
0(0) \\
0(0)\end{array}$ & $\begin{array}{l}2(4.9) \\
0(0) \\
0(0) \\
0(0)\end{array}$ & $\begin{array}{c}0(0) \\
2(100) \\
0(0) \\
0(0)\end{array}$ & $\begin{array}{l}0(0) \\
0(0) \\
0(0) \\
0(0)\end{array}$ & $\begin{array}{l}0(0) \\
0(0) \\
0(0) \\
0(0)\end{array}$ & $\begin{array}{l}0 \\
0 \\
0 \\
0\end{array}$ & $\begin{array}{c}(n=41 ; 95.4) \\
(n=2 ; 4.6) \\
(n=0 ; 0) \\
(n=0 ; 0)\end{array}$ \\
\hline Pre-frail & & & & & & & $(n=104)$ \\
\hline $\begin{array}{l}\text { No alteration } \\
\text { Questionable } \\
\text { Mild } \\
\text { Moderate }\end{array}$ & $\begin{array}{c}72(91.1) \\
0(0) \\
0(0) \\
0(0)\end{array}$ & $\begin{array}{c}2(2.5) \\
4(36.4) \\
0(0) \\
0(0)\end{array}$ & $\begin{array}{c}4(5.1) \\
6(54.5) \\
8(88.9) \\
0(0)\end{array}$ & $\begin{array}{c}1(1.3) \\
1(9.1) \\
1(11.1) \\
5(100)\end{array}$ & $\begin{array}{l}0(0) \\
0(0) \\
0(0) \\
0(0)\end{array}$ & $\begin{array}{l}2 \\
0 \\
0 \\
2\end{array}$ & $\begin{array}{c}(n=79 ; 76.0) \\
(n=11 ; 10.6) \\
(n=9 ; 8.6) \\
(n=5 ; 4.8)\end{array}$ \\
\hline Frail & & & & & & & $(n=35)$ \\
\hline $\begin{array}{l}\text { No alteration } \\
\text { Questionable } \\
\text { Mild } \\
\text { Moderate }\end{array}$ & $\begin{array}{c}13(86.7) \\
0(0) \\
0(0) \\
0(0)\end{array}$ & $\begin{array}{c}2(13.3) \\
2(50.0) \\
0(0) \\
0(0)\end{array}$ & $\begin{array}{c}0(0) \\
2(50.0) \\
6(75.0) \\
0(0)\end{array}$ & $\begin{array}{c}0(0) \\
0(0) \\
1(12.5) \\
7(87.5)\end{array}$ & $\begin{array}{c}0(0) \\
0(0) \\
1(12.5) \\
1(12.5)\end{array}$ & $\begin{array}{l}2 \\
2 \\
3 \\
1\end{array}$ & $\begin{array}{c}(n=15 ; 42.8) \\
(n=4 ; 11.4) \\
(n=8 ; 22.9) \\
(n=8 ; 22.9)\end{array}$ \\
\hline
\end{tabular}

CDR: Clinical Dementia Rating. *Rate of progression calculated only for participants evaluated at 12-month follow up (deaths and individuals missing to follow up excluded); **death presented only for descriptive purposes.

On average, frail individuals had lower MMSE scores at baseline in comparison to the other groups as well as a proportionally greater reduction in MMSE scores at the end of the 12-month period. In the analysis of the change in MMSE score, statistically significant differences were found between frail and non-frail individuals as well as between frail and pre-frail individuals $(p=0.005)$, whereas no statistically significant difference was found between non-frail and pre-frail individuals. Frail individuals had a 4.6-fold greater risk of a reduction in MMSE score in comparison to non-frail individuals (Tab 4).

The proportion of individuals who progressed to more severe degrees of cognitive impairment in the 12-month period as assessed by the CDR classification was $9.4 \%$ among non-frail individuals, $16.3 \%$ among pre-frail individuals, and $20 \%$ among frail individuals. However, no statistically significant differences among groups were found with regard to the change in CDR classification $(\mathrm{p}=0.393)$. 
Table 3. Comparison of incidence and progression rates of cognitive impairment among classifications of frailty*.

\begin{tabular}{|c|c|c|c|c|}
\hline & $\begin{array}{l}\text { Non-frail } \\
(n=43) \\
n(\%)\end{array}$ & $\begin{array}{l}\text { Pre-frail } \\
(n=104) \\
n(\%)\end{array}$ & $\begin{array}{l}\text { Frail } \\
(n=35) \\
n(\%)\end{array}$ & $p$-value \\
\hline $\begin{array}{l}\text { Cognitive impairment**} \\
\text { Continued with negative screening } \\
\text { Progressed to positive screening }\end{array}$ & $\begin{array}{c}39(95.1) \\
2(4.9)\end{array}$ & $\begin{array}{c}72(91.1) \\
7(8.9)\end{array}$ & $\begin{array}{c}13(86.7) \\
2(13.3)\end{array}$ & 0.675 \\
\hline $\begin{array}{l}\text { CDR } \\
\text { No change in CDR } \\
\text { Change in CDR }\end{array}$ & $\begin{array}{c}39(90.6) \\
4(9.4)\end{array}$ & $\begin{array}{l}87(83.7) \\
17(16.3)\end{array}$ & $\begin{array}{l}28(80) \\
7(20)\end{array}$ & 0.393 \\
\hline $\begin{array}{l}\text { MMSE, mean } \pm S D \text {; (min-max) } \\
\text { Baseline } \\
\text { After } 12 \text { months }\end{array}$ & $\begin{array}{c}24.02 \pm 4.03 \\
(10-30) \\
25.33 \pm 3.24 \\
(14-30)\end{array}$ & $\begin{array}{l}21.19 \pm 5.48 \\
(6-29) \\
20.70 \pm 6.35 \\
(0-30)\end{array}$ & $\begin{array}{l}16.71 \pm 5.79 \\
(2-29) \\
15.94 \pm 7.01 \\
(0-29)\end{array}$ & 0.005 \\
\hline
\end{tabular}

SD: standard deviation; min: minimum; max: maximum; MMSE: Mini Mental State Exam; CDR: Clinical Dementia Rating.

*Comparisons among classifications of frailty only performed for participants evaluated at 12-month follow-up (deaths and individuals missing to follow-up excluded); **individuals with positive screening at baseline excluded from calculation of incidence.

Table 4. Relative risk of incidence of cognitive decline in 12-month period*.

\begin{tabular}{lccccccccc} 
Classification of & \multicolumn{2}{c}{ Incidence of cognitive impairment } & \multicolumn{3}{c}{ Decline on MMSE } & \multicolumn{2}{c}{ Decline on CDR } \\
\cline { 2 - 9 } frailty & $\mathrm{p}$-value & $\mathrm{RR}$ & $95 \% \mathrm{Cl}$ & $\mathrm{p}$-value & $\mathrm{RR}$ & $95 \% \mathrm{Cl}$ & $\mathrm{p}$-value & $\mathrm{RR}$ & $95 \% \mathrm{Cl}$ \\
\hline Non-frail & 0.675 & 1.0 & - & 0.005 & 1.0 & - & 0.393 & 1.0 \\
Pre-frail & & 1.4 & $0.31-6.7$ & & 3.5 & $1.51-8.4$ & - & 1.7 \\
Frail & & 1.2 & $0.18-8.3$ & & 4.6 & $1.93-11.2$ & $0.63-4.9$ & 2.1 & $0.68-6.7$ \\
\hline
\end{tabular}

RR: relative risk; Cl: confidence interval; MMSE: Mini Mental State Exam; CDR: Clinical Dementia Rating

*Analysis of relative risk only performed for participants evaluated at the 12-month follow-up.

\section{DISCUSSION}

The present cohort study conducted with communitydwelling older adults demonstrated that frailty is associated with a subsequent decline in cognitive function within a 12-month period when measured using the MMSE. However, no statistically significant differences among the different classifications of frailty were detected regarding the decline in cognitive function when assessed using the CDR.

Two different forms of evaluating cognitive decline in a 12-month period were used in the present study. Although frail individuals exhibited proportionally greater decline in comparison to non-frail individuals using both assessment tools, the difference between classifications of frailty was only significant when using the MMSE. The risk of frail individuals exhibiting a decline in cognitive function in a 12-month period, as evaluated by the MMSE, was approximately fivefold greater in comparison to non-frail individuals. Previous studies with a longer follow-up period also report an association between frailty and cognitive decline measured by the MMSE ${ }^{4,6,8}$.

The 12-month period may not have been sufficient to demonstrate an association between frailty and cognitive decline when measured by the CDR, as this assessment tool involves more than an evaluation of cognitive aspects ${ }^{9,12,13,28}$. The CDR classifies older adults in degrees of impairment based on evaluations that integrate both cognitive and behavioral aspects as well as the extent to which these aspects interfere in activities of daily living ${ }^{9,12,13,28}$. Moreover, the CDR classification involves information on both the older adult and caregiver ${ }^{9,13}$.
Although the proportion of new cases of cognitive impairment in a 12-month period was greater among the group of frail individuals, especially in comparison with non-frail individuals, this difference did not achieve statistical significance. However, studies with a longer follow-up period report a longitudinal association between frailty and the incidence of both mild cognitive impairment ${ }^{7}$ and dementia ${ }^{5,6}$. It is therefore likely that the follow-up period in the present study was not long enough to demonstrate an association because the progression to cognitive impairment is quite heterogeneous among individuals ${ }^{9-11,29}$. Another factor that may have affected this result was the fact that the present study only investigated the incidence of a positive screening for cognitive impairment and not the occurrence of better established cognitive alterations, such as mild cognitive impairment and dementia ${ }^{5-7}$.

The association between frailty and cognitive impairment is widely discussed in the literature ${ }^{3-7}$. While studies have shown that frailty may be a predictor of mild cognitive impairment, dementia and cognitive decline, there seems to be a biological association between the onset of cognitive decline and frailty ${ }^{3-7}$. Thus, frailty may not be a predictor of the onset of cognitive impairment and the two conditions may instead share the same physiopathological mechanisms ${ }^{3-7}$. Therefore, the combination of frailty and cognitive impairment may exacerbate an individual's vulnerability and influence the subsequent decline in cognitive function ${ }^{5,7}$.

The hypothesis of shared physiopathological mechanisms is based on the fact that both frailty and cognitive impairment involve inflammatory activation mechanisms 
and neuroendocrine dysregulation ${ }^{3-7}$. Chronic inflammation is believed to play a central role in the pathogenesis of frailty ${ }^{1,30}$ and high levels of inflammatory cytokines and acute phase inflammatory reactants have also been associated with cognitive impairment ${ }^{1,30}$. Likewise, neuroendocrine dysregulation is involved in both conditions ${ }^{1,30}$. Nonetheless, common biological pathways hardly explain the relationship between frailty and cognitive impairment. As both are complex conditions, it is more likely that other factors are also involved ${ }^{6}$. Therefore, further studies are needed to clarify the association between frailty and cognitive impairment and explain why different older adults evolve differently ${ }^{5}$.

The present study has limitations that should be addressed. There was no evaluation of diseases or conditions associated with cognitive impairment, as different conditions may imply heterogeneous effects on cognitive function $^{29}$. Another limitation regards that fact that no control was performed for factors that can influence cognitive function, such as depression'.

The findings of the present study demonstrate an association between frailty and a subsequent decline in cognitive function when measured by the MMSE, even within a short period of time (12 months). However, no significant associations were found between frailty and the incidence of cognitive impairment evaluated using the CDR. The association between frailty and cognitive impairment needs to be investigated further. The findings of future studies can assist in the establishment of prevention strategies and health promotion programs aimed at vulnerable older adults.

\section{References}

1. Fried LP, Xue QL, Cappola AR, et al. Nonlinear multisystem physiological dysregulation associated with frailty in older women: implications for etiology and treatment. J Gerontol A Biol Sci Med Sci 2009;64:1049-1057.

2. Fried LP, Tangen C, Walston J, Newman A. Frailty in older adults: evidence for a phenotype. J Gerontol A Biol Sci Med Sci 2001;56:M146-156.

3. Avila-Funes JA, Helmer C, Amieva $\mathrm{H}$, et al. Frailty among communitydwelling elderly people in France: the three-city study. J Gerontol A Biol Sci Med Sci 2008;63:1089-1096.

4. Jacobs JM, Cohen A, Ein-Mor E, Maaravi Y, Stessman J. Frailty, cognitive impairment and mortality among the oldest old. J Nutr Health Aging 2011;15:678-682.

5. Avila-Funes JA, Amieva H, Barberger-Gateau P, et al. Cognitive impairment improves the predictive validity of the phenotype of frailty for adverse health outcomes: the three-city study.J Am Geriatr Soc 2009;57:453-461.

6. Buchman AS, Boyle PA, Wilson RS, Tang Y, Bennett DA. Frailty is associated with incident Alzheimer's disease and cognitive decline in the elderly. Psychosom Med 2007;69:483-489.

7. Boyle PA, Buchman AS, Wilson RS, Leurgans SE, Bennett DA. Physical frailty is associated with incident mild cognitive impairment in community-based older persons. J Am Geriatr Soc 2010;58:248-255.

8. Samper-Ternent R, Al Snih S, Raji MA, Markides KS, Ottenbacher KJ. Relationship between frailty and cognitive decline in older Mexican Americans. J Am Geriatr Soc 2008;56:1845-1852.

9. Morris JC,Storandt M, MillerJP, et al. Mild cognitive impairment represents early-stage Alzheimer disease. Arch Neurol 2001;58:397-405.

10. Farias ST, Mungas D, Reed BR, Harvey D, DeCarli C. Progression of mild cognitive impairment to dementia in clinic-vs community-based cohorts. Arch Neurol 2009;66:1151-1157.

11. Aretouli E, Okonkwo OC, Samek J, Brandt J. The fate of the 0.5s: predictors of 2-year outcome in mild cognitive impairment. J Int Neuropsychol Soc 2011;17:277-288.

12. Montaño MBMM, Ramos, LR. Validity of The Portuguese version of Clinical Dementia Rating. Rev Saude Publica 2005;39:912-917.

13. Morris JC. The clinical dementia rating (CDR): current version and scoring rules. Neurology 1993;43:2412-2414.

14. Nitrini R, Caramelli P, Porto CS, et al. Brief cognitive battery in the diagnosis of mild Alzheimer's disease in subjects with medium and high levels of education. Dementia Neuropsychol 2007;1:32-36

15. Takada LT, Caramelli P, Fichman H, et al.Comparison between two tests of delayed recall for the diagnosis of dementia. Arq Neuropsiquiatr 2006;64:35-40.
16. Folstein MF, Folstein SE, Mchugh PR. "Mini-mental state". A practical method for grading the cognitive state of patients for clinician. $J$ Psychiatr Res 1975;12:189-198.

17. Brucki SM, Nitrini R, Caramelli P, Bertolucci PH, Okamoto IH. Suggestions for utilization of the mini-mental state examination in Brazil. Arq Neuropsiquiatr 2003;61:777-781.

18. Vitiello APP, Ciríaco JGM, Takahashi DY, Nitrini R, Caramelli P. Brief cognitive evaluation of patients attended in a general neurological outpatient clinic. Arq Neuropsiquiatr 2007;65:299-303.

19. Lipschitz DA. Screening for nutritional status in the elderly. Prim Care 1994:21:55-67.

20. Yesavage JA, Brink TL, Rose TL, et al. Development and validation of a geriatric screening scale: a preliminary report. J Psychiatr Res 19821983;17:37-49.

21. Almeida OP, Almeida SA. Reliability of the Brazilian version of abbreviated form of Geriatric Depression Scale (GDS) short form. Arq Neuropsiquiatr 1999;57:421-426.

22. Alexopoulos GS, Abrams RC, Young RC, Shamoian CA. Cornell Scale for Depression in dementia. Biol Psychiatry 1988;23:271-284.

23. Carthery-Goulart MT, Areza-Fegyveres R, Schultz RR, et al. Brazilian version of the Cornell depression scale in dementia. Arq Neuropsiquiatr 2007;65:912-915.

24. Lino VT, Pereira SR, Camacho LA, Ribeiro Filho ST, Buksman S. Crosscultural adaptation of the Independence in Activities of Daily Living Index (Katz Index). Cad Saude Publica 2008;24:103-112.

25. Lawton MP, Brody EM. Assessment of older people: self-maintaining and instrumental activities of daily living. Gerontologist 1969;9:179-186.

26. Avlund K, Lund R, Holstein BE, Due P. Social relations as determinant of onset of disability in aging. Arch Gerontol Geriatr 2004;38:85-99.

27. Gill TM, Hardy SE, Williams CS. Underestimation of disability in community-living older persons. J Am Geriatr Soc 2002: 50:1492-1497.

28. Chaves ML, Camozzato AL, Godinho C, et al. Validity of the clinical dementia rating scale for the detection and staging of dementia in Brazilian patients. Alzheimer Dis Assoc Disord 2007;21:210-217.

29. Mungas D, Beckett L, Harvey D, et al. Heterogeneity of cognitive trajectories in diverse older persons. Psychol Aging 2010; 25:606-619.

30. Walston J, McBurnie MA, Newman A. Frailty and activation of the inflammation and coagulation systems with and without clinical comorbidities: results from the Cardiovascular Health Study. Arch Intern Med 2002;162:2333-2341. 